\title{
An experiment on sulphur
}

\section{Dr. Theodor Gross}

To cite this article: Dr. Theodor Gross (1880) An experiment on sulphur, Philosophical Magazine Series 5, 9:53, 79-80, DOI: 10.1080/14786448008626803

To link to this article: http://dx.doi.org/10.1080/14786448008626803

册 Published online: 28 Apr 2009.

Submit your article to this journal

Џ Article views: 2

Q View related articles $₫$ 
The nature of the enveloping gas may, besides, be very approximately determined. In fact, if a few air-bubbles are let into the vacuum-apparatus at the moment when the exhaustion is finished, the orange-red coloration characteristic of hyponitric vapour appears in the receiver: the gaseous sheath is therefore formed principally of binoxide of nitrogen.

What are the determining causes of the formation of the gaseons sheath around the metal? What is the nature of the influences which afterwards keep up its adherence? I am undertaking investigations bearing upon these questions*.-Comptes Rendus de l'Académie des Sciences, Nov. 10, 1879, t. lxxxix. pp. 783-786.

\section{AN EXPERIMENT ON SULPHUR. BY DR. THEODOR GROSS.}

In the following I take leave to make a brief communication on an experiment with sulphur, by which I have obtained a substance which, accordiug to my judgment, is new, and cannot be further analyzed by several of the most powerful chemical reagents.

Some purest commercial milk of sulphur was mixed with linseedoil, in the proportion of one part of sulphur to not quite one part of oil, and then gently heated in a very wide bowl. The mixture swells up strongly, emitting disagreeable fumes, and leaves a black porous mass behind in large pieces which will not ignite under conditions under which sulphur by itself would burn briskly. The black mass was then finely pulverized and, with pure concentrated sulphuric acid, heated gently during several hours till it boiled. After a brisk liberation of sulphurous acid, I obtained a liquid which in its most concentrated state has the appearance of thick fluid sulphur. More attenuated, it appears clear and pure yellowish red; still more diluted, brownish yellow. Into this diluted acid liquid, sulphuretted hydrogen was passed, and thereby, at least in part, a bright-brown precipitate thrown down. This is soluble in sulphide of ammonium, and also in hot potash-lye. On the other hand, even a hot mixture of hydrochloric acid and chlorate of potass dissolves. but little of it.

When the precipitate is heated in air, the sulphur burns up, and the residue is a black substance likewise very indifferent to inorganic acids. This, on being beated in the combustion-boat in a tube of difficultly fusible glass, with a current of oxygen passing through it, till the glass was bright-red-hot, proved fire-proof. Similarly heated in chlorine it became tirst brown, and after longer action white; and part of it was deposited as a sublimate immediately behind the hottest place of the glass tube. By heating it in hydrogen the original black substance was then again obtained.

* This memoir will be inserted in extenso in the Annales de Chimie et do Physique. 
Since the black substance is precipitable from its combination with or solution in sulphuric acid by sulphuretted hydrogen as a precitate soluble in sulphide of ammonium, it belongs to a certain well known group of elements, from all of which it is essentially distinguished by the above-mentioned characters. Hence I feel called upon to regard it as new. It is, moreover, either not at all altered, or undergoes no further resolution, by strong acids, oxygen, chlorine, and hydrogen. Since such a substance as the one described is not contained in linseed-oil, it can only be derived from the sulphur; and the question immediately arises how it is present in the latter. If sulphur is an element, our substance can only have been mixed with it. But as a trifling mixture of something with an element that occurs in abundance is out of the question (for 1020 grams of sulphur give an amply sufficient quantity of the abovedescribed substance for the chemical reactions and experiments), one would suppose that, since it is not mixed as such with the sulphur, it occurs therein in a combination which could not be resolved by distillation \&c., goes with sulphur into its combination with alkali or alkaline earth, is likewise precipitated by acid, and, finally, could only be detected by the experiment with linseed-oil. Yet such a supposition would not be a probable one. Sulphur separated from chemically pure gases with the utmost precaution does not behave otherwise to linseed-oil than milk of sulphur, and, as I in March last communicated to the Physical Society of this place, can by itself alone be heated so that, employed even in minute quantities (such as about half a gram), it leaves a black residue in which carbon as carbonic acid can be identified. Further, I have observed (inter alia) that sulphur, distilled under certain conditions, yields peculiar gaseous products which could not be brought into accordance with any known inorganic sulphur combination. From all these reasons it has become very doubtful to me that sulphur is an element. This question, however, shall not be further pursued here, since I hope shortly to publish further experiments for its discussion, and since the purpose of this communication was chiefly to make known the above-described substance, which $I$ hold to be new.

Permit me here to mention that, besides sulphur, I am also investigating other bodies, and have observed with phosphorus especially something similar to what I have observed in the case of sulphur.-Cammunicated to the Berlin Academy of Sciences by Prof. Helmholtz. Monatsbericht der k. p. Alkademie der Wissenschaften zu Berlin, August 1879, pp. 788-790. 